\title{
Qualidade da água em reservatórios prediais. Contributos para o PSA da Póvoa de Varzim
}

\author{
Patrícia Silveira ${ }^{a *}$, José Vieira $^{b}$ \\ a Câmara Municipal da Póvoa de Varzim, Póvoa de Varzim, Portugal \\ b CTAC - Centro do Território, Ambiente e Construção, Universidade do Minho, Braga, \\ Portugal
}

\section{Resumo}

A exploração de sistemas de abastecimento de água para consumo humano é uma atividade de grande complexidade pela necessidade de se garantir uma melhoria contínua de eficácia e eficiência no serviço prestado aos consumidores. De acordo com a Organização Mundial da Saúde, a forma mais eficaz de garantir uma água segura pode concretizar-se através da implementação de planos de segurança da água que contemplam a descrição detalhada do sistema de abastecimento, a identificação de perigos, a avaliação do risco e o estabelecimento de medidas necessárias para os controlar, abarcando todas as etapas do sistema, desde a bacia de captação até à torneira do consumidor. Uma das grandes dificuldades na aplicação deste conceito situase nas redes prediais urbanas, uma vez que a propriedade privada limita a responsabilidade das entidades gestoras dos sistemas públicos em assegurar uma responsabilidade direta sobre a qualidade da água nestas redes. O presente trabalho de investigação teve como objetivo avaliar a qualidade da água em reservatórios prediais e em torneiras de consumidores na cidade da Póvoa de Varzim, constituindo-se um contributo para a implantação de um plano de segurança da água nesta cidade portuguesa.

Pallavras-Chave: Plano de segurança da água, avaliação do risco, reservatórios, redes prediais.

doil: $10.22181 / a e r .2019 .0503$

* Autor para correspondência

E-mail: patriciasilveira@cm-pvarzim.pt 


\title{
Water quality in household storage tanks. A contribution for the water safety plan of Póvoa de Varzim
}

\author{
Patrícia Silveira ${ }^{a *}$, José Vieira ${ }^{b}$ \\ a Câmara Municipal da Póvoa de Varzim, Póvoa de Varzim, Portugal \\ b CTAC - Centro do Território, Ambiente e Construção, Universidade do Minho, Braga, \\ Portugal
}

\section{Abstract}

Drinking water supply systems management is an activity of great complexity due to the need to ensure a continuous improvement of efficiency and effectiveness in the service provided to consumers. According to the World Health Organization, the most effective way to ensure good safe drinking water can be achieved through the implementation of water safety plans which is a comprehensive risk assessment and risk management approach that encompasses all steps in a drinking-water supply chain, from catchment to consumer. Notwithstanding that the water supplied by the water utility is safe to drink, the water quality could be affected in the internal plumbing systems due to various factors, such as the drinking water tank is not properly cleaned, or the internal water supply system is contaminated due to stagnation of water or use of inappropriate plumbing materials. In view of this, a research work was developed in order to evaluate the quality of water in building storage tanks and internal distribution system in the city of Póvoa de Varzim, constituting a contribution to the implementation of a water safety plan in this Portuguese city.

Keywords: water safety plan, risk assessment, household storage tanks, building pipe systems.

doil: 10.22181/aer.2019.0503

* Corresponding author

E-mail: patriciasilveira@cm-pvarzim.pt 


\section{Introdução}

De acordo com a Organização Mundial da Saúde (OMS), a forma mais efetiva de garantir a segurança da água para consumo humano pode ser alcançada através da implementação de planos de segurança da água (PSA), que constituem uma abordagem integrada de avaliação e gestão do risco que abrange todos as etapas de um sistema de abastecimento de água desde a bacia de captação até à torneira do consumidor.

Com a publicação das Diretrizes para a qualidade da água para consumo humano em 2004 e 2011 (3..$^{a}$ e $4 .^{a}$ edições, respetivamente), a OMS estabeleceu um quadro de referência que, numa abordagem integrada, incorpora novos conceitos e metodologias de avaliação e gestão do risco num sistema de abastecimento, incluindo a implementação de Planos de Segurança da Água (WHO 2004, WHO 2011a).

Também a Diretiva Europeia 2015/1787 (UE, 2015), transposta para a legislação Portuguesa pelo Decreto-Lei 152/2017 (Legislação Portuguesa, 2017), reconhece vantagens e recomenda que se adote este tipo de metodologias. Esta recomendação fundamenta-se no seguinte:

- "Desde 2004, a OMS tem desenvolvido a abordagem relativa ao plano de segurança da água, que se baseia na avaliação do risco e nos princípios de gestão do risco estabelecidos nas suas diretrizes para a qualidade da água para consumo humano. Tais diretrizes, juntamente com a norma EN 15975-2, relativa à segurança nos sistemas de abastecimento de água, constituem princípios reconhecidos a nível internacional em que se baseiam a produção, a distribuição, o controlo e a análise dos parâmetros da água para consumo humano";

- "A fim de controlar os riscos para a saúde humana, os programas de controlo devem assegurar a existência de medidas ao longo de toda a cadeia de abastecimento de água e analisar as informações provenientes de massas de água utilizadas para a captação de água potável. As obrigações gerais aplicáveis aos programas de controlo devem colmatar o fosso existente entre captação e abastecimento de água".

As tarefas envolvidas na elaboração e implementação de um PSA estão atribuídas às entidades gestoras dos sistemas de abastecimento. No entanto, há componentes do controlo da qualidade da água previstas no PSA, tal como proposto pela OMS, que geralmente estão fora do perímetro das competências e responsabilidades das entidades gestoras. São os casos do controlo de qualidade da água bruta nas bacias de captação (da competência do regulador ambiental) e nas redes prediais (domínio de propriedade privada).

A qualidade da água bruta é um fator-chave para garantir água segura para o seu consumo. Na realidade, o uso da água, o uso do solo e a atividade humana poluidora na área da bacia de captação têm impactos significativos na qualidade das águas superficiais e subterrâneas e, portanto, no nível e complexidade das estações de tratamento necessárias para garantir que a água produzida nestas infraestruturas seja segura e aceitável para os consumidores. A proteção das fontes de água bruta deve ser vista como a primeira, e muitas vezes a mais importante, barreira para evitar a contaminação microbiana, química e radiológica das fontes de água potável (Vieira et al. 2011, Vieira e Pinho 2011, WHO 2016).

Apesar da água fornecida pela entidade gestora poder ser segura para o consumidor, a qualidade da água pode ser deteriorada nas redes prediais devido a vários fatores como, por exemplo, o reservatório de água não estar devidamente limpo ou o sistema interno de abastecimento de água estar contaminado devido à estagnação de água ou uso de materiais de construção inadequados nas redes internas. Por essa razão, a OMS editou várias publicações, alertando para o facto da má conceção de projeto e deficiente gestão de sistemas de água em edifícios poder causar surtos de doenças (WHO 2011b) e 
diversos estudos têm sido desenvolvidos para tratar esta problemática de segurança da água em redes domiciliárias (Völker et al. 2010, Exner and Hartemann 2009, Zietz et al. 2007, Aish 2013).

O presente trabalho de investigação focou-se, especificamente, na avaliação da qualidade da água em reservatórios de serviço prediais e em torneiras de consumidores, através da sua monitorização num número considerável de edifícios da cidade da Póvoa de Varzim, pretendendo-se concluir sobre os riscos da água consumida nesses edifícios. Este estudo é, também, justificado pelas características balneares da cidade, cuja população triplica no Verão, o que lhe confere um grau de sazonalidade que determina a utilização diferenciada dos reservatórios prediais em diferentes épocas do ano.

Desta forma, procura caracterizar-se os possíveis riscos associados ao consumo de água após armazenamento em reservatórios de sistemas prediais para posterior distribuição domiciliária. Assume, assim, a observação da problemática da possível degradação da qualidade da água distribuída para consumo humano, devido a armazenagem imprópria antes da torneira do consumidor, bem como o contributo do tipo de material e da idade das tubagens para a segurança da água na distribuição.

Por outro lado, espera-se que os resultados obtidos possam vir a constituir-se como base para a melhoria dos processos de monitorização da qualidade da água, bem como para a apresentação de propostas de normas municipais que atendam a uma adequada gestão do risco no domínio particular das redes prediais de abastecimento, perspetivando-se a sua aplicabilidade a outros municípios, à escala nacional.

\section{Metodologia}

\subsection{Abordagem de gestão do risco em sistemas de abastecimento}

No desenvolvimento do trabalho, desenvolveu-se uma metodologia específica para caracterizar aspetos físico-químicos e microbiológicos associados à água de consumo humano dos sistemas prediais com sistemas de armazenamento de água, através de análises laboratoriais. Pretendeu-se sinalizar os riscos decorrentes do armazenamento de água em reservatórios prediais, onde se presume não existir qualquer controlo, e avaliá-los através de uma metodologia de priorização.

O estudo enquadrou-se nos princípios de identificação e priorização dos riscos plausíveis que podem verificar-se num sistema de abastecimento, desde a origem de água bruta até à torneira do consumidor, como sugerido em Vieira e Morais (2005), focando-se na etapa rede de distribuição (Figura 1).

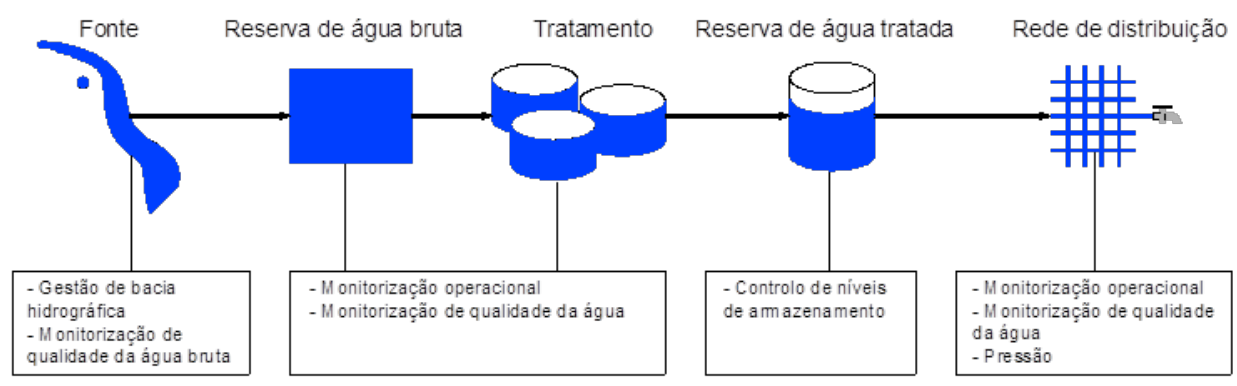

Figura 1. Gestão do risco em sistemas de abastecimento de água (Vieira e Morais 2005) 


\subsection{Caso de estudo}

\subsection{1 Área de estudo}

A área de estudo selecionada para a realização deste trabalho foi a cidade da Póvoa de Varzim, localizada na região norte de Portugal, com uma população residente de 28420 habitantes (censos de 2011), que aumenta significativamente no verão, em período balnear.

\subsubsection{Amostragem}

Dentro do universo de 5510 edifícios (censos de 2011) foi realizada uma averiguação prévia para identificar os que possuem reservatórios de água, a partir da qual foi possível definir a dimensão da amostra de edifícios a contemplar no esforço laboratorial a realizar (Figura 2).

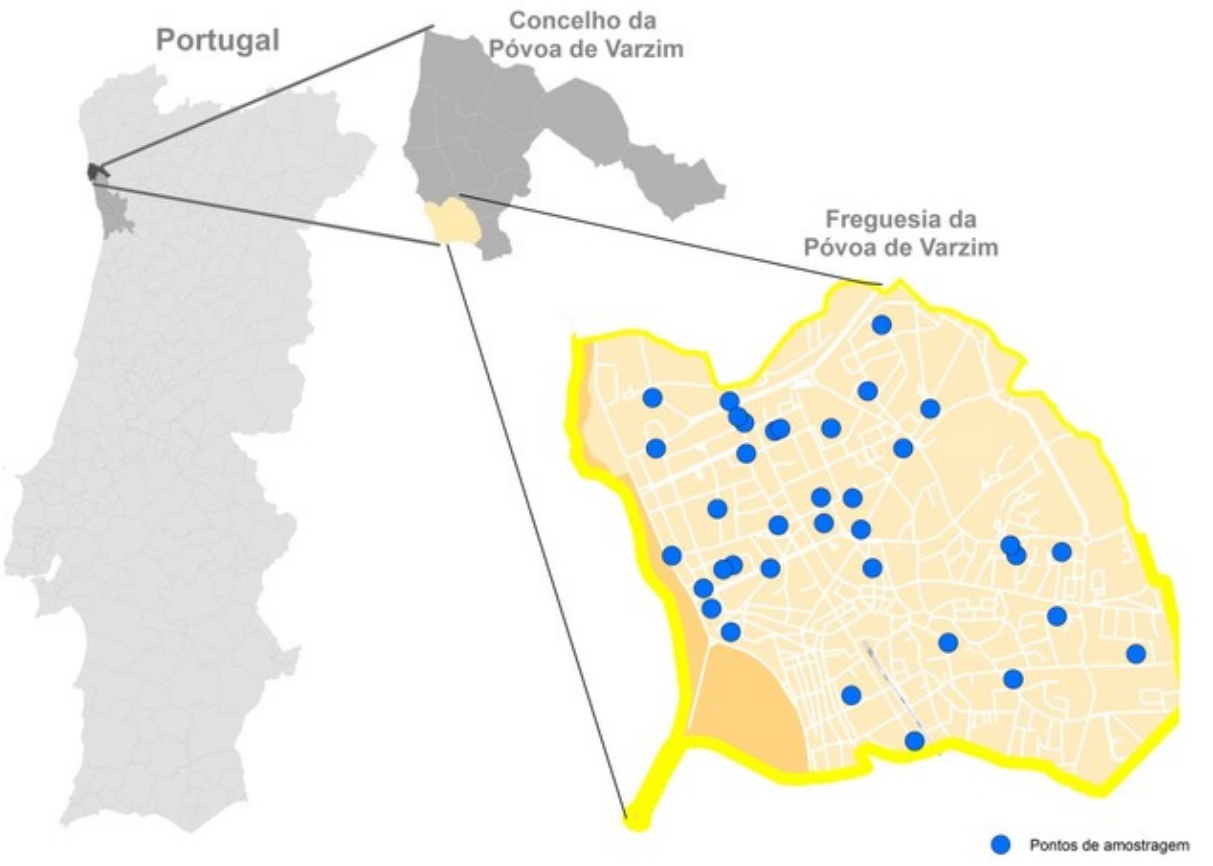

Figura 2. Distribuição dos pontos de amostragem estabelecidos em Póvoa de Varzim

Foi estabelecida uma amostra de 45 edifícios com reservatório, distribuídos por toda a cidade da Póvoa de Varzim, selecionados por forma a obter uma amostra de edifícios novos e antigos, com diferentes números de apartamentos e andares, contemplando grandes consumidores e consumidores domésticos. Considerando a dificuldade em definir a representatividade da amostragem neste tipo de investigação, assumiu-se que o presente estudo tem carácter exploratório. Nos consumidores domésticos (33 edifícios), consideraram-se dois pontos de amostragem (um a jusante do reservatório e outro numa torneira de consumidor) para averiguar da responsabilidade da rede domiciliária numa possível deterioração da qualidade da água consumida. Nos grandes consumidores (12 edifícios), considerou-se apenas um ponto de amostragem no reservatório, assumindose que, desta forma, estava garantida a necessária representatividade. A amostra considerada representa cerca de $1 \%$ do total de edifícios. Este número de edifícios representa uma percentagem maior se forem considerados apena o número de alojamentos com reservatório predial.

Foi, ainda, considerada uma amostra comparativa relativamente a edifícios abastecidos diretamente da rede pública, sem reservatório. Neste caso foram analisados os resultados obtidos no PCQA (plano de controlo de qualidade da água) aprovado oficialmente. 


\subsubsection{Metodologia de amostragem}

O método adotado para a realização das amostras foi o seguinte:

- Amostragem e análises realizadas por laboratório acreditado, garantindo a utilização de métodos analíticos e limites de quantificação de acordo com a legislação em vigor;

- Verificação e avaliação da existência e periodicidade de manutenção, desinfeção e higienização dos reservatórios de água em sistemas prediais;

- Verificação e avaliação da existência de PCQA para a água armazenada;

- Verificação dos parâmetros controlados e da periodicidade de amostragem para averiguação da qualidade da água distribuída (caso exista PCQA);

- Verificação da qualidade da água distribuída em redes prediais com reservatórios: controlo analítico dos principais parâmetros físico-químicos e microbiológicos constantes das normas legais e coincidentes com os adotados pelo PCQA:

$\circ \mathrm{pH}$, condutividade, turvação, desinfetante residual, ferro, alumínio, cobre, cádmio, cheiro, sabor, dureza, n. ${ }^{\circ}$ de colónias a $22^{\circ} \mathrm{C}, \mathrm{n} \cdot{ }^{\circ}$ de colónias a $37^{\circ} \mathrm{C}$, bactérias coliformes fecais, bactérias coliformes totais, Escherichia coli, Enterococos intestinais, Clostridium perfringens e Legionella pneumophila. Apesar de a percepção sensorial ser uma característica essencial para a avaliação da qualidade da água para consumo humano, é necessário averiguar, em simultâneo, as características físico-químicas e microbiológicas, recorrendose, para tal, a um conjunto de parâmetros legislados e analisá-los. De todos os parâmetros que compõem a legislação, e não havendo a necessidade de se realizar uma amostragem completa, foram triados aqueles que se assumiram fundamentais para se perceber se a qualidade da água distribuída se coaduna com os fins a que se destina.

- Periodicidade de amostragem: Foi realizada uma amostragem em cada um dos 45 pontos (edifícios) selecionados. Apesar de ser pertinente a concretização de, pelo menos, duas análises em cada ponto, uma no Inverno e outra no Verão, para se perceberem as dinâmicas de alteração na qualidade da água em conformidade com as condições climáticas, considerou-se inviável esta periodicidade pois, em caso de verificação de incumprimento dos valores paramétricos legais, seria necessário informar a Administração do Condomínio para que procedesse à rápida limpeza e desinfeção do reservatório. Caso houvesse recusa ou relutância, por parte da Administração do Condomínio, à reposição da qualidade da água distribuída pela entidade gestora, à entrada do sistema predial, ter-se-ia de efetuar o reporte à Autoridade de Saúde, o que poderia obrigar a encetar os processos necessários para que se garantir a segurança da água, podendo até, em situações extremas, ser interrompido o fornecimento até regularização da situação. Em conformidade com estas considerações, tornar-se-ia desnecessária uma segunda análise, uma vez que, em situação de inconformidade, seria efetuada uma intervenção imediata que ludibriaria o âmbito do estudo proposto. Por isso, a campanha de amostragem foi realizada nos meses de Março a Maio de 2018, tendo sido medida a temperatura média da água de $20^{\circ} \mathrm{C}$;

- Verificação das tubagens dos edifícios em estudo e avaliação do contributo da sua idade e material para a possível degradação da qualidade da água distribuída;

- A recolha de dados engloba a realização de inquéritos aos consumidores, por forma a compreender a sua perceção relativamente à qualidade da água que consomem.

- Aferição da bondade de propostas para o controlo de qualidade da água e periodicidade de limpeza em reservatórios de água de sistemas prediais. 
Os resultados das análises físico-químicas e microbiológicas relativas aos locais selecionados constam do Quadro 1.

Quadro 1. Resultados obtidos nos locais selecionados e análise comparativa em relação ao PCQA

\begin{tabular}{|c|c|c|c|c|c|c|c|c|c|c|c|}
\hline \multirow[t]{2}{*}{ Parâmetros } & \multirow[t]{2}{*}{ Unidades } & \multicolumn{2}{|c|}{$\begin{array}{l}\text { Resultados nos } \\
\text { Reservatórios }\end{array}$} & \multicolumn{2}{|c|}{$\begin{array}{l}\text { Resultados a } \\
\text { Jusante dos } \\
\text { Reservatórios }\end{array}$} & \multicolumn{2}{|c|}{$\begin{array}{l}\text { Resultados } \\
\text { Grandes } \\
\text { Consumidores }\end{array}$} & \multicolumn{2}{|c|}{ Resultados PCQA } & \multirow[t]{2}{*}{$\begin{array}{c}\text { Valor } \\
\text { Paramétrico } \\
\text { (VP) }\end{array}$} & \multirow[t]{2}{*}{$\begin{array}{c}\text { \%Cumprimento } \\
\text { do VP }\end{array}$} \\
\hline & & Mínimo & Máximo & Mínimo & Máximo & Mínimo & Máximo & \begin{tabular}{|l|} 
Mínimo \\
\end{tabular} & Máximo & & \\
\hline Alumínio & $\mu \mathrm{g} / \mathrm{l} \mathrm{Al}$ & 19 & 100 & 15 & 98 & 14,9 & 28,3 & $<10$ & 35 & 200 & $100 \%$ \\
\hline \begin{tabular}{c|} 
Bactérias \\
coliformes Totais
\end{tabular} & \begin{tabular}{|l|} 
ufc $/ 100 \mathrm{ml}$ \\
amostra
\end{tabular} & 0 & 0 & 0 & 13 & 0 & 0 & 0 & 0 & 0 & $98,48 \%$ \\
\hline Cádmio & $\mu \mathrm{g} / \mathrm{l} C \mathrm{~d}$ & $<0,50$ & $<0,50$ & $<0,50$ & $<0,50$ & $<0,50$ & $<0,50$ & --- & --- & 5,0 & $100 \%$ \\
\hline Cheiro a $25^{\circ}$ & \begin{tabular}{|l|}
$\begin{array}{l}\text { Factor de } \\
\text { diluição }\end{array}$ \\
\end{tabular} & $<1$ & $<1$ & $<1$ & $<1$ & $<1$ & $<1$ & $<1$ & $<1$ & 3 & $100 \%$ \\
\hline $\begin{array}{c}\text { Cloro residual } \\
\text { livre in situ }\end{array}$ & $\mathrm{mg} / \mathrm{l} \mathrm{Cl} 2$ & 0,3 & 0,7 & 0,1 & 0,7 & 0,5 & 1,6 & 0,3 & 0,9 & --- & $100 \%$ \\
\hline $\begin{array}{l}\text { Clostridium } \\
\text { perfringens }\end{array}$ & $\begin{array}{l}\text { ufc/100ml } \\
\text { amostra }\end{array}$ & 0 & 0 & 0 & 0 & 0 & 0 & 0 & 0 & 0 & $100 \%$ \\
\hline Cobre & $\mathrm{mg} / \mathrm{l} \mathrm{Cu}$ & $<0,005$ & 0,04 & $<0,005$ & 0,0232 & 0,018 & 0,01 & 0,016 & 0,056 & 2,0 & $100 \%$ \\
\hline $\begin{array}{c}\text { Bactérias } \\
\text { Coliformes fecais }\end{array}$ & $\begin{array}{l}\text { ufc/100ml } \\
\text { a mostra }\end{array}$ & 0 & 0 & 0 & 0 & 0 & 0 & --- & --- & 0 & $100 \%$ \\
\hline $\begin{array}{c}\text { Condutividade } \\
\text { eléctrica }\end{array}$ & $\mu \mathrm{S} / \mathrm{cm}$ & 110 & 236 & 111 & 159 & 105 & 126 & 95 & 136 & 2500 & $100 \%$ \\
\hline Dureza Total & $\begin{array}{l}\mathrm{mg} / \mathrm{l} \\
\mathrm{CaCO} 3 \\
\end{array}$ & 12,4 & 57 & 36,2 & 56 & 24,8 & 57 & 51 & 60 & --- & $100 \%$ \\
\hline $\begin{array}{l}\text { Enterococus } \\
\text { Intestinais }\end{array}$ & $\begin{array}{l}\text { ufc/100ml } \\
\text { amostra }\end{array}$ & 0 & 0 & 0 & 0 & 0 & 0 & 0 & 0 & 0 & $100 \%$ \\
\hline Escherichia coli & \begin{tabular}{|l|} 
ufc/100ml \\
amostra
\end{tabular} & 0 & 0 & 0 & 0 & 0 & 0 & 0 & 0 & 0 & $100 \%$ \\
\hline Ferro & $\mu \mathrm{g} / \mathrm{l} \mathrm{Fe}$ & $<60$ & 200 & $<60$ & 110 & $<60$ & 150 & $<60$ & $<60$ & 200 & $100 \%$ \\
\hline $\begin{array}{c}\text { Número de } \\
\text { colónias a } 22^{\circ} \mathrm{C} \\
\end{array}$ & $\begin{array}{l}\text { ufc/ml } \\
\text { amostra }\end{array}$ & 11 & 47 & 2 & 2 & 0 & 1 & 0 & 198 & --- & $100 \%$ \\
\hline $\begin{array}{c}\text { Número de } \\
\text { colónias a } 37^{\circ} \mathrm{C}\end{array}$ & $\begin{array}{l}\text { ufc/ml } \\
\text { amostra }\end{array}$ & 2 & 40 & 3 & 2 & 0 & 0 & 0 & $>300$ & --- & $100 \%$ \\
\hline Legionella spp. & $\begin{array}{l}\text { ufc/L } \\
\text { amostra }\end{array}$ & 0 & 0 & 0 & 0 & 0 & 0 & --- & -- & -- & $100 \%$ \\
\hline pH & \begin{tabular}{|l|} 
Escala \\
Sorensen
\end{tabular} & 7,6 & 8,6 & 7,6 & 8 & 7,3 & 8,3 & 7,3 & 7,8 & $6,5-9,5$ & $100 \%$ \\
\hline Sabor a $25^{\circ}$ & \begin{tabular}{|l|}
$\begin{array}{l}\text { Factor de } \\
\text { diluição }\end{array}$ \\
\end{tabular} & $<1$ & $<1$ & $<1$ & $<1$ & $<1$ & $<1$ & $<1$ & $<1$ & 3 & $100 \%$ \\
\hline Turvação & 1 NTU & $<1$ & 1,1 & $<1$ & $<1$ & $<1$ & $<1$ & $<1$ & $<1$ & 4 & $100 \%$ \\
\hline
\end{tabular}

Da análise dos valores constantes do Quadro 1 constata-se que os resultados analíticos estão em conformidade com as normas de qualidade estabelecidas na legislação em vigor para água destinada a consumo humano.

Refere-se que, no ponto 9 da torneira de um consumidor doméstico, foi detetado um incumprimento regulamentar, que se assume estar associado à contaminação da rede predial. Relativamente ao parâmetro "cloro residual livre" não foi integralmente respeitado o valor recomendado pela legislação em vigor, em alguns pontos de amostragem. Há, ainda, a referir dois pontos onde se verificaram valores de Ferro próximos do valor limite legal, que podem ser associados à deterioração da rede de condutas prediais.

Os bons resultados obtidos estão relacionados com políticas municipais de garantia de qualidade da água aos consumidores da cidade da Póvoa de Varzim, nomeadamente:

- Níveis de desinfetante residual elevados, que garantem a qualidade microbiológica apesar dos fatores de estagnação, materiais de construção inadequados, idade das tubagens e inexistência de um plano de controlo da qualidade da água;

- Campanha de sensibilização forte, no que concerne à problemática da Legionella pneumophila, que promoveu a implementação de medidas de minimização de más práticas verificadas anteriormente, com impacto na qualidade da água consumida;

- Água de elevada qualidade distribuída pela entidade gestora, associada a uma prática sistemática de controlo de qualidade das infraestruturas físicas. 
O estudo efetuado revelou que o cuidado que se tem atualmente com os reservatórios no que concerne a manutenção, desinfeção e higienização - tanto da água contida nestes como das áreas técnicas que os albergam, é muito reduzido ou até, por vezes, inexistente.

Relativamente a inquéritos já realizados, refere-se que, na generalidade, os consumidores têm a perceção de uma boa qualidade da água distribuída, referindo-se, apenas o sabor a cloro (desinfetante residual) como possível fator inibitório de consumo.

Deve notar-se que os resultados obtidos correspondem a amostragens realizadas no período de Março a Maio. Considerando expectável que haja uma maior renovação da água reservada no período balnear, a existir alteração da qualidade da água, previsivelmente esta seria mais favorável.

\section{Considerações finais}

Considerando a falta de informação e de legislação sobre o controlo de qualidade de sistemas de distribuição predial, nomeadamente o seu envelhecimento, e sendo escassas as operações de limpeza e desinfeção destas infraestruturas, entendeu-se realizar um estudo alargado e representativo, no sentido de se averiguar da segurança da água consumida por consumidores domésticos e grandes consumidores da cidade da Póvoa de Varzim.

Apesar dos bons resultados obtidos, foram encontradas diversas práticas inadequadas relacionadas com os sistemas prediais de reserva de água. Torna-se, por isso, necessário regulamentar esta utilização, por forma a garantir a vigilância dos fatores de risco, bem como a informação e o aconselhamento aos consumidores.

Importa referir, no entanto, que, apesar dos bons resultados obtidos, não é tácito que a segurança esteja completamente garantida, configurando-se pertinente a análise a parâmetros como trihalometanos e hidrocarbonetos, bem como a outros que possam demonstrar os efeitos das situações verificadas durante o estudo, nomeadamente dos usos indevidos dos espaços de acomodação dos reservatórios prediais e da sua manutenção. É ainda pertinente proceder à verificação de períodos de estagnação da água nos reservatórios e à verificação da forma em que o desinfetante residual se apresenta.

Com este estudo pretendeu-se, cumulativamente dar um contributo para a elaboração do PSA, bem como para uma proposta de normas municipais que atendam a uma adequada gestão do risco no domínio particular das redes de abastecimento prediais.

A metodologia e os resultados obtidos neste trabalho sugerem a sua generalização a outros municípios portugueses, tendo em conta a heterogeneidade das suas realidades específicas.

\section{Agradecimentos}

Os autores agradecem à Câmara Municipal da Póvoa de Varzim o apoio financeiro e logístico que permitiu a realização deste estudo. Sem este apoio seria inviável a execução de um estudo com a abrangência e significância como o que foi desenvolvido. 


\section{Referências}

Aisha A.M. (2013). Drinking water quality assessment of the Middle Governorate in the Gaza Strip, Palestine. Water Resources and Industry 4, 13-20.

Legislação Portuguesa (2017). Decreto-Lei no 152/2017, de 7 de dezembro que transpõe para a ordem jurídica interna: a Diretiva (UE) n. ${ }^{\circ}$ 2015/1787 da Comissão, de 6 de outubro de 2015 que altera os anexos II e III da Diretiva 98/83/CE do Conselho relativa à qualidade da água destinada ao consumo humano e a Diretiva n. ${ }^{\circ}$ 2013/51/EURATOM do Conselho, de 22 de outubro de 2013, que estabelece requisitos para a proteção da saúde do público em geral no que diz respeito às substâncias radioativas presentes na água destinada ao consumo humano.

Exner M., Hartemann P. (2009). Summary of the second meeting of the International Forum on Water Hygiene in Buildings (IFOWAHB) FROM 01 TO 02.06.2007 in Stockholm. Int. J. Hyg. Environ. Health. 212, 449-458.

UE (2015), Diretiva (UE) 2015/1787, da Comissão, de 6 de Outubro de 2015, que altera os anexos II e III da Diretiva 98/83/CE, do Conselho, relativa à qualidade da água destinada ao consumo humano. Bruxelas, 2015.

Vieira J.M.P., Morais C.M. (2005). Planos de segurança da água para consumo humano. Edição IRAR, ISBN: 972-99354-5-9, p.173. Lisboa.

Vieira J.M.P., Breach B., Hirata R. (2011). Chapter 4. Developing a catchment water safety plan. In: Drinking Water Quality Management from Catchment to Consumer, Ed. B. Breach. IWA Publishing, London.

Vieira J.M.P., Pinho J.L.S. (2014). River water quality modelling in developing a catchment water safety plan. 11th International Conference on Hydroinformatics, HIC 2014, New York, USA.

Völker S., Schreiber C., Kistemann T. (2010). Drinking water quality in household supply infrastructure-a survey of the current situation in Germany. Int. J. Environ. Health Res. 213, 204-209.

WHO (2004). Guidelines for Drinking-water Quality (3 $3^{\text {rd }}$ Edition). World Health Organization, Geneva.

WHO (2011a). Guidelines for Drinking-water Quality (4 ${ }^{\text {th }}$ Edition). World Health Organization, Geneva.

WHO (2011b). Water safety in buildings. Ed. D. Cunliffe, J. Bartram, E. Briand, Y. Chartier, J. Colbourne, D. Drury, J. Lee, B. Schaefer and S. Surman-Lee. World Health Organization, Geneva.

WHO (2016). Protecting surface water for health. Identifying, assessing and managing drinkingwater quality risks in surface-water catchments. World Health Organization, Geneva.

Zietz B.P., Lass J., Suchenwirt R. (2007). Assessment and management of tap water lead contamination in Lower Saxony, Germany. Int. J. Environ. Health Res. 17 (6) 407-418. 